\title{
The Role of Situation Criticality in Affecting the Effect of Cognitive Load on Drivers' Brake responses: A Driving Simulator Based Study
}

\author{
Qingwan Xue, ${ }^{1}$ Xuedong Yan $\mathbb{D}^{2},{ }^{2}$ Yi Zhao, ${ }^{3}$ and Yuting Zhang ${ }^{4}$ \\ ${ }^{1}$ Beijing Key Laboratory of Urban Intelligent Traffic Control Technology, North China University of Technology, \\ Beijing 100144, China \\ ${ }^{2}$ MOT Key Laboratory of Transport Industry of Big Data Application Technologies for Comprehensive Transport, \\ School of Traffic and Transportation, Beijing Jiaotong University, Beijing 100044, China \\ ${ }^{3}$ Standards and Metrology Research Institute, China Academy of Railway Sciences Corporation Limited, Beijing 100081, China \\ ${ }^{4}$ School of Highway, Chang'an University, Xi'an 710064, China \\ Correspondence should be addressed to Xuedong Yan; xdyan@bjtu.edu.cn
}

Received 3 April 2020; Revised 22 September 2020; Accepted 1 October 2020; Published 22 October 2020

Academic Editor: Rocío de Oña

Copyright ( 2020 Qingwan Xue et al. This is an open access article distributed under the Creative Commons Attribution License, which permits unrestricted use, distribution, and reproduction in any medium, provided the original work is properly cited.

A dramatic increase in talking on the phone whilst driving has been seen over the past decades, which posed a significant safety threat on the whole society consequently. Studies on the topic regarding the effect of phone conversations on drivers' driving performances have never come to a cease, especially on the studies of drivers' brake response times. However, few studies focus on the relationship between situation criticality and the effect of cognitive load on drivers' brake responses. To better understand it, a driving simulator experiment with two braking scenarios corresponding to two levels of situation criticality was conducted in this study. Participants were asked to follow a lead vehicle as they normally did and answer arithmetic problems (simple and complex) in three phone modes (baseline, hands-free, and handheld) in the meantime. Drivers' brake response times to the lead vehicle under five conditions were collected and fitted in accumulator models, in which visual looming and brake lights onset were included as the sensory cues. Results demonstrated that the previously proposed mechanistically explicit simulation model was able to predict drivers' brake response times on different levels of cognitive load and the increased effect of cognitive load on drivers' brake response times in less critical situations was demonstrated in this paper as well.

\section{Introduction}

Driver distraction is one of the main reasons for road accidents, accounting for $10 \%, 37 \%, 10.7 \%$, and $16 \%$ in New Zealand, Spain, Canada, and the USA, respectively $[1,2,3,4]$. Among all types of distractions, while driving, the distraction caused by cell phones is relatively high [5]. In a survey conducted by Wogalter and Mayhorn [6], it was reported that $81 \%$ of the participants $(n=191)$ used a cell phone while driving. In China, the proportion of road incidents caused by cell phone use in 2014 is $47.2 \%$ [7]. Due to the common use of cell phones and the potential risk they may cause, approximately 44 countries have banned the use of handheld phones while driving $[8,9,10]$.
Studies focusing on the effect of cell phones conversation whilst driving over the past decades have shown that driving performances were greatly degraded $[11,12,13,14$, $15,16,17,18]$, for example, reaction time to events, lateral and longitudinal vehicle control, and glance behaviour. One of the most often studied performances, as a result of cell phone conversations, is the reaction time. Generally, drivers' reaction times became larger while involved in cell phone conversations [19, 20, 21, 22, 23, 24]; for example, Caird et al. [23] found an average increase of $0.25 \mathrm{~s}$ in reaction time for all types of phone-related tasks in a comprehensive metaanalysis study. Haque and Washington [24] found that drivers' reaction times were $40 \%$ longer in the distracted condition compared with the baseline (not distracted). 
In addition to the comparison between cell phone conversation and no phone conversation, the effect of different cell phone types (hands-free vs. handheld) on reaction time has been studied as well [19, 25, 26, 27, 28]. Some studies found that talking on a handheld phone had a longer reaction time than talking on a hands-free phone [25, 29]. However, different opinions existed as it was found that talking on a hands-free phone did not offer any advantages on drivers' responses when compared with a handheld one $[19,26,27,28]$; for example, by conducting a peripheral detection task while driving on the motorway, Patten et al. [26] found no benefit of a hands-free phone over a handheld phone. Instead, a significant increase in reaction time was found when the conversation content is complex compared with a simple conversation. It seems that the content and the level of emotional intensity attached to the conversation have a significant influence on the reduction of drivers' brake responses [30]. The same conclusions could be found in the studies of Caird et al. [23] and Choudhary and Velaga [31] as well.

As summarised here, both the effects of conversation mode and conversation complexity on drivers' reaction times have been studied by dozens of papers. However, it seems that few researchers focus on the relation between situation criticality and the effect of phone conversation on drivers' brake response time. Actually, the phone conversation distracted drivers by producing cognitive load on the drivers $[16,19]$. Engström [32] verified that the effect of cognitive load on drivers' brake responses could be affected by situation criticality by conducting a simple linear regression model. Initial time headway was adopted in the linear regression model to measure the situation criticality. Results demonstrated that the longer the initial time headway, the larger the effect of cognitive load on drivers' brake responses. However, why does this effect depend on initial time headway and how drivers perceive time headway information and use it to determine when to apply braking were still not clear. To further explain the key underlying mechanisms, Engström et al. [33] outlined a mechanistic model with the data from the meta-analysis. Visual looming, which is produced by the sudden braked lead vehicle moving towards the subject was adopted in this model to measure situation criticality. The results obtained in this study offered a straightforward explanation for why the effect of cognitive load on drivers' brake responses depends on situation criticality. However, of the studies included in the data, both Alm and Nilsson [34] and Strayer and Drews [20] conducted studies between younger and older drivers. Slower reactions were found for older drivers in both of the two studies, which made it difficult to distinguish whether the effect of long reactions was attributed to cognitive load or the age, or a mixed effect of them. Xue et al. [35] conducted a comparison between the multilevel model and the accumulator model. The accumulator model tested in that paper not only provided a powerful means of predicting drivers' brake response time, but also a plausible account of the mechanism underlying drivers' uses of visual looming information for deciding on brake activation.

To further test the relation between situation criticality and the effect of cognitive load on drivers' brake responses and better understand the underlying mechanism on drivers' brake responses, data collected from a driving simulator study was fitted in the accumulator model in this paper. Comparing with the study of Engström et al. [33], this paper developed in three principal ways. (1) Participants' ages were restricted in this experiment to eliminate the possible effect of age on drivers' responses. (2) Three phone types and two kinds of conversation complexity were included in the experiment to examine whether the proposed model in Engström et al. [33] could provide a good prediction for different combinations of cognitive load levels. (3) The lead vehicle would brake twice in each conversation condition, with the first brake assumed to be less critical and the second brake assumed to be more critical. The increased effect of cognitive load on drivers' brake response in noncritical lead vehicle braking scenarios would be tested (see Section 2.2 for detailed experiment design).

\section{Methods}

2.1. Equipment. The equipment used in this experiment is Beijing Jiaotong University (BJTU) driving simulator (as shown in Figure 1). The simulator was produced by Realtime Technologies Inc., USA. It is composed of a realistic cabin of Ford Focus and automatic gearbox, gas/brake pedal, and other components are in full accordance with the real vehicle. The simulator with a shaking simulation system and a linear motion base is capable of operating with a single degree of freedom (the rotation of pitch). The simulator adopted in this study was very similar to the one used by the Western Transportation Institute (WTI), where both its physical and behavioural fidelity were demonstrated. Studies have shown that no statistically significant difference was found for the brake response time between simulator studies and test track, which supported the relative validity of the driving simulator. The driving scenarios are designed with SimVista and projected on five screens to realise a driver's 300 -degree field of front view, each screen with a resolution of $1400 \times 1050$ pixels.

2.2. Scenario Design. The experimental road designed in this study was a two-lane urban road with a speed limit of $80 \mathrm{~km} /$ h. The lead vehicle was stationary on the driving lane with its brake lights on. When the participant was $55 \mathrm{~m}$ behind the lead vehicle, the lead vehicle began to accelerate and followed the predefined speed (as shown in Figure 2). The lead vehicle braked (always with its brake lights on) twice in each drive, with the deceleration rate of $4 \mathrm{~m} / \mathrm{s}^{2}$ and $6 \mathrm{~m} / \mathrm{s}^{2}$, accordingly. The first deceleration point was $465 \mathrm{~m}$ away from the lead vehicle's start point (around $40 \mathrm{~s}$ ), and the second deceleration point was $210 \mathrm{~m}$ away from the first one. The lead vehicle reduced its speed when it drove to the deceleration point and followed the predefined speed until it reached the next one. High-density traffic flow was designed on the other lane to simulate the real traffic situation.

The purpose of this study is to see the role of situation criticality in affecting the effect of cognitive load on drivers' brake response. Three cell phone conversation modes, that 


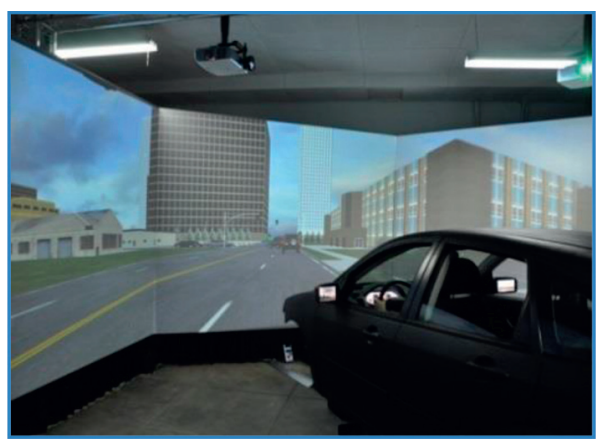

(a)

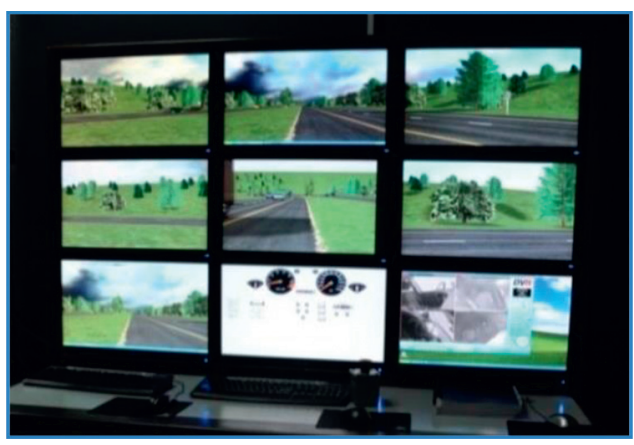

(b)

FIGURE 1: Illustration of the driving simulator system.

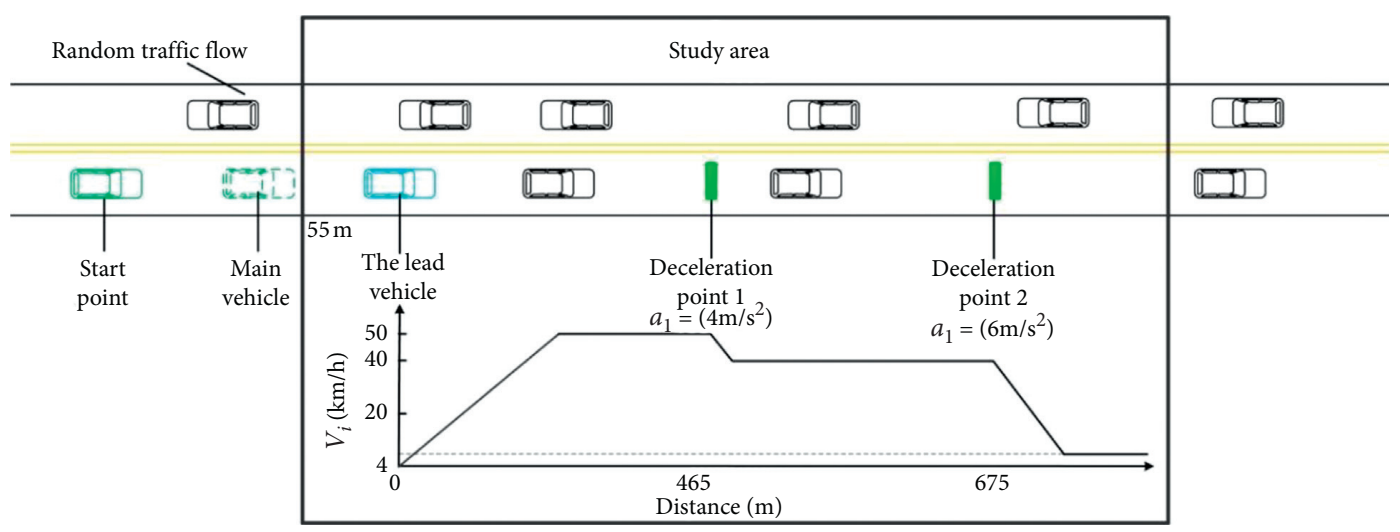

Figure 2: Details of the experimental road and study area.

is, baseline (no cell phone conversation involved), handsfree cell phone, and handheld cell phone, together with two conversation contents (simple vs. complex) were designed to produce different levels of cognitive load on participants. The cell phone adopted in this study was a Nokia E5 one, with dimensions of $115 \mathrm{~mm} \times 58.9 \mathrm{~mm} \times 12.8 \mathrm{~mm}$. The phone conversion distracted drivers by asking some simple arithmetic problems, that is, single-digit and double-digit addition and subtraction, corresponding to the two levels of conversation difficulty. Participants were instructed to answer the phone as fast and accurate as they could. For the formal experiment, the duration of one drive was about $5 \mathrm{~min}$, and each participant drove five times under five cell phone use conditions so that participants in this experiment had a total driving time of about $25 \mathrm{~min}$. To eliminate the experiment order effect, the order of each drive was counterbalanced between each participant. Definitions of the two conversation modes and the two conversation contents are stated below.

Hands-free conversation with simple content $\left(\mathrm{HF}_{\mathrm{S}}\right)$ : the cell phone was placed on the dashboard and drivers can hear through a loudspeaker without using a hand to hold it. Drivers were asked to answer problems of single-digit addition and subtraction; for example, what is the answer to two and five?

Hands-free conversation with complex content $\left(\mathrm{HF}_{\mathrm{C}}\right)$ : the only difference between $\mathrm{HF}_{\mathrm{S}}$ and $\mathrm{HF}_{\mathrm{C}}$ is the difficulty of arithmetic problems; for example, what is the answer to twelve and twenty-seven?

Handheld conversation with simple content $\left(\mathrm{HH}_{\mathrm{S}}\right)$ : the cell phone should be held in the driver's hand and positioned close to the ear. The arithmetic problems were similar to the ones in $\mathrm{HF}_{\mathrm{S}}$.

Handheld conversation with complex content $\left(\mathrm{HH}_{\mathrm{C}}\right)$ : the conversation mode is the same as in $\mathrm{HH}_{\mathrm{S}}$ while the conversation content is similar to the ones in $\mathrm{HF}_{\mathrm{C}}$.

2.3. Participants and Procedure. A total of 45 participants were recruited for this experiment. Three of them were not able to complete the experiment due to the motion sickness. Thus, behaviour data of 42 participants (21 males and 21 female) aging from 30 to 40 years $(M=34.33$, S.D. $=2.99)$ were collected eventually. Each participant held a valid Chinese driving license and had driving mileage of $30,000 \mathrm{~km}$ at least. Upon arriving at the BJTU Driving Simulator Lab, participants were briefed on the requirements of the experiment and completed an informed consent form. Participants were told to follow a white vehicle as they normally would and they were given at least 10 minutes of driving training, including accelerating and decelerating to a specific speed. Participants were not aware of the sudden brake of the lead vehicle in the formal experiment and they were not allowed to overtake the white vehicle as well. For 
the formal experiment, each participant had to drive five times and would rest for at least 5 min between the drives. Participants who completed the experiment successfully would receive $200 \mathrm{RMB}$ (around 28 USD) as their payment.

\subsection{Modelling Drivers' Brake Response Time}

2.4.1. Accumulator Model. In this study, drivers' brake response time was measured from the lead vehicle's brake onset to the brake response of the following vehicle. The model adopted here to investigate drivers' brake response mechanism underlying was the accumulator model, which was based on the evidence accumulation framework developed by Markkula [36]. In the accumulator model, there is a gradual process of accumulation of evidence over time. And the accumulator model included both looming cues and brake lights provided a better model fitting than the looming-only version of the model [35]. Thus, in this study, both visual looming and the lead vehicle's brake light onset were included in the accumulator model, as two types of sensory evidence. The looming signal in this paper was represented by $\dot{\theta}$ and $\tau^{-1}$, respectively. The angular projection of an object on the subject's retina is defined as $\theta$, with $\dot{\theta}$ being the angular expansion rate [37]. And $\tau^{-1}=\dot{\theta} / \theta$; the optical variables $\theta$ and $\dot{\theta}$ can be calculated by the following formulas [37]:

$$
\begin{aligned}
& \theta=2 \cdot \arctan \left(\frac{W}{2 d}\right), \\
& \dot{\theta}=-\frac{\mathrm{W} v_{\text {rel }}}{\left(d^{2}+W^{2} / 4\right)},
\end{aligned}
$$

in which $W$ is the width of the lead vehicle, $d$ is the distance from the driver's eyes to the tail of the lead vehicle, and $v_{\text {rel }}$ is the relative speed of the two vehicles. And the brake lights input was represented by $b$, which is set to 1 from the lead vehicle's brake onset. An accumulator model including both visual looming and drivers' reactions to brake lights was thus defined:

$$
\frac{\mathrm{d} A(t)}{\mathrm{d} t}=W_{l} L(t)+W_{B} b+C-M+\varepsilon(t),
$$

where $W_{l}$ and $W_{B}$ are weights of the two inputs and $\varepsilon(t)$ is noise, which follows $\varepsilon(t) \sim N(0, \sigma)$. A braking response is generated when $A(t) \geq A_{0}=1 . L(t)$ is one piece of looming evidence and represented by $\dot{\theta}(t)$ or $\tau^{-1}(t)$. $C$ represents five phone conversation conditions, that is, $C_{B}$ is no phone condition; $C_{H F_{-} S}$ and $C_{H_{-} C}$ are hands-free conversations with simple and complex content; $C_{H_{H} \_}$and $C_{H_{H} C}$ are handheld conversations with simple and complex content, respectively. $-M$ can be interpreted as the sum of negative gating together with all the other available evidence for and against the drivers' brake action [36]. To perform maximumlikelihood fitting of the mechanistic models on the dataset, all model parameters were searched on a uniformly spaced grid. For each combination of parameters, 200 simulations were run for each of the five conversation conditions. A numerical distribution of predicted brake response time was thus generated per scenario, for each combination of parameters and the maximum-likelihood parameterisation; that is, the one which yielded probability distributions under which the observed data were maximally probable, was retained. To simplify the best parameterisation searching process, $W_{B}$ and $-M$ are combined into one parameter, represented by $W_{B}$ and the search range for each parameter was listed in Table 1.

2.4.2. Data for Model Fitting. In this experiment, 210 $(42 \times 5)$ recordings were collected in total. However, as the headway distance was not controlled in the experiment, not all the participants were able to follow the lead vehicle when the lead vehicle's brake onset. Recordings with time headway larger than $5 \mathrm{~s}$ were thus excluded. Therefore, only 84 recordings were included for the first braking scenario and 132 recordings were kept for the second braking scenario. As a follow-up study of Engström et al. [33], recordings within each drive were sorted into nine groups regarding their initial time headways (ITHWs). Drivers' mean brake response times (BRTs) within each ITHW group were calculated as the observations to fit the accumulator model. Table 2 shows the data prepared for model fitting.

\section{Results}

3.1. The First Braking Scenario. Figure 3 shows the distribution of BRTs under baseline and four conversation conditions. The black squares and whiskers show average BRTs and related standard deviation on 95\% confidence interval, respectively. Paired $t$-tests were conducted between each of the two conditions with a significant level at 0.1. Significant differences can be found between baseline and all the other four conversation conditions. Overall, drivers' brake response times increased when they were involved in conversation tasks, whatever phone mode and conversation content are. But when drivers are involved in phone conversations, the difference between phone modes (hands-free vs. handheld) or conversation content (simple vs. complex) is not significant. For the same conversation content, for example, for the simple group, no significant difference is found between hands-free conversation and handheld conversation. Even for the same conversation type, the difference between simple and complex content is not significant.

As Engström [32] tested, the effect of cognitive load on drivers' response to the lead vehicle depends heavily on the ITHWs. The correlation between BRTs and ITHWs in this experiment was then examined by Spearman's nonparametric test. As shown in Figure 4, significant correlations between ITHWs and BRTs are found in all the five conditions. To further explore the effect of cognitive load on the stimuli-response mechanism underlying, accumulator models fitting on the mean BRTs within each ITHW group using $\dot{\theta}$ and $\tau^{-1}$ are adopted, respectively. Table 3 shows the best parameterisation obtained for the grouped dataset using grid search with maximum-likelihood estimation. The AIC here indicated that the model with visual looming represented by $\dot{\theta}$ fitted slightly better than the one represented by 
TABLE 1: Parameter search range.

\begin{tabular}{lrr}
\hline Parameter & \multicolumn{1}{c}{ Searched values } \\
& \multicolumn{1}{c}{$\tau^{-1}$} & \\
\hline$W_{l}$ & $\{20,21,22, \ldots, 40\}$ & $\{1,2,3, \ldots, 10\}$ \\
$W_{B}$ & $\{-1,-0.9,-0.8, \ldots, 1\}$ & $\{-1,-0.9,-0.8, \ldots, 1\}$ \\
$C_{B}$ & $\{0,0.02,0.04, \ldots, 0.3\}$ & $\{0,0.02,0.04, \ldots, 0.3\}$ \\
$C_{H F \_S}$ & $\{0,0.02,0.04, \ldots, 0.3\}$ & $\{0,0.02,0.04, \ldots, 0.3\}$ \\
$C_{H F \_C}$ & $\{0,0.02,0.04, \ldots, 0.3\}$ & $\{0,0.02,0.04, \ldots, 0.3\}$ \\
$C_{H H_{-} S}$ & $\{0,0.02,0.04, \ldots, 0.3\}$ & $\{0,0.02,0.04, \ldots, 0.3\}$ \\
$C_{H H_{-} C}$ & $\{0,0.02,0.04, \ldots, 0.3\}$ & $\{0,0.02,0.04, \ldots, 0.3\}$ \\
$\sigma_{a}$ & $\{0.12,0.14, \ldots, 0.4\}$ & $\{0.12,0.14, \ldots, 0.4\}$ \\
\hline
\end{tabular}

TABLE 2: The dataset for analysis.

\begin{tabular}{lcc}
\hline & First braking scenario & Second braking scenario \\
\hline Lead vehicle's speed $(\mathrm{m} / \mathrm{s})$ & 13.88 & 11.11 \\
Lead vehicle's deceleration rate $\left(\mathrm{m} / \mathrm{s}^{2}\right)$ & 4 & 6 \\
Following vehicle's average speed $(\mathrm{m} / \mathrm{s})$ & 14 & 11.28 \\
Lead vehicle's width $(\mathrm{m})$ & 2 & 2 \\
Time headway range $(\mathrm{s})$ & 84 & $\{1,1.5,2,2.5,3,3.5,4,4.5,5\}$ \\
Number of recordings & & 132 \\
\hline
\end{tabular}

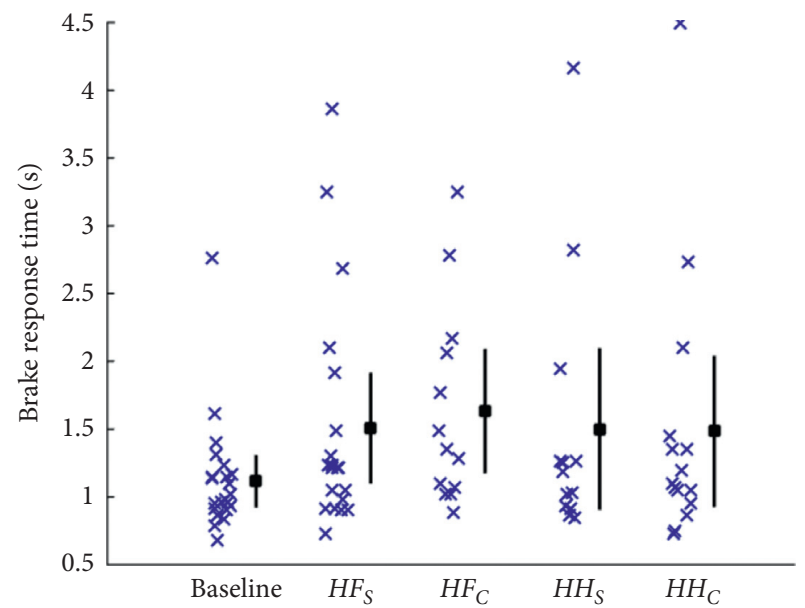

FIgURE 3: Drivers' brake responses to the first braking scenario under five conditions (black square and whisker indicate the mean value and standard deviation on $95 \% \mathrm{CI}$, resp.).

$\tau^{-1}$ (197.8 vs. 202.4$)$. With the best parameterisation listed in Table 3, Figures 5 and 6 show the mean BRTs generated by the simulation for different groups of ITHWs, using $\dot{\theta}$ and $\tau^{-1}$, respectively. The shaded areas represent the standard deviation of the modelled BRTs and the lines in the central shaded areas represent the average modelled BRTs. Observed mean BRTs are included in the plots as well, indicated by asterisks. Generally, mean BRTs become larger with the increase of the ITHWs and the BRTs variabilities increase with the ITHWs as well. Meanwhile, when comparing no phone with hands-free conditions, the effect of cognitive load on BRTs increases with the ITHWs (reflected by the steeper slope). However, the increased effect of cognitive load on BRTs is not significant between no phone and handheld conditions, especially for the handheld conversation with complex content.
3.2. The Second Braking Scenario. Figure 7 shows all the 132 recordings of the second braking scenario under five conversation conditions. It should be noticed that drivers react faster in this group compared to the first braking scenario. In the first braking scenario, drivers generally spent $1.5 \mathrm{~s}$ to respond to the lead vehicle's sudden brake when they were involved in a phone conversation. In the second braking scenario, drivers reacted faster even when they were talking on the phone, and it could be found that drivers' mean BRTs in five conditions are very close to each other. No significant difference is found between each of the five conditions by conducting a paired $t$-test. Again, significant correlations between ITHWs and BRTs could be found in all the five conditions. Results are shown in Figure 8. Table 4 shows the best parameterisation for the second braking scenario. With the results shown in Table 4, better model fitting could be found when using $\tau^{-1}$ compared with $\dot{\theta}$ (143.4 vs. 167.6). The modelled mean BRTs and related variabilities are shown in Figures 9 and 10. Similar to the first braking scenario, both modelled mean BRTs and the variabilities increase with the ITHWs. However, no increased effect of cognitive load on BRTs is observed between no phone and any type of conversation conditions, using neither $\dot{\theta}$ nor $\tau^{-1}$.

\section{Discussion}

One goal of the study was to investigate whether the model proposed in Engström et al. [33] could be implemented on different levels of cognitive load. A driving simulator experiment with three phone conversation modes (baseline, hands-free, and handheld) and two conversation contents (simple and complex) was designed to produce different levels of cognitive load. Results in Section 3.1 and Section 3.2 indicated that the previously proposed stochastic mechanism model fitted well on different levels of cognitive load. The two measures adopted in the accumulator model to 


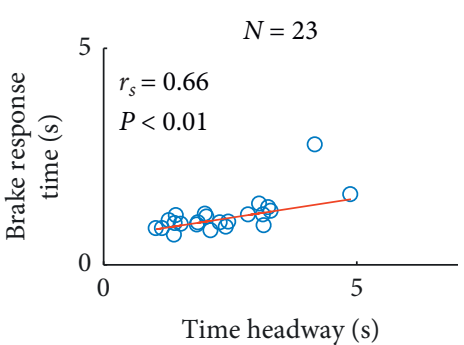

(a)

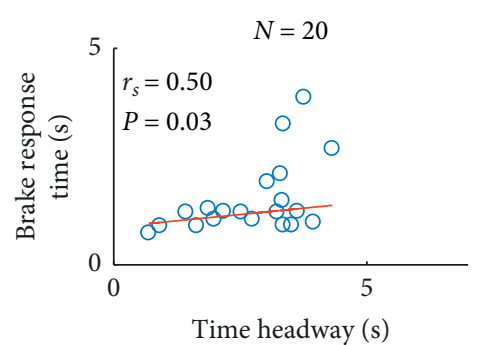

(b)

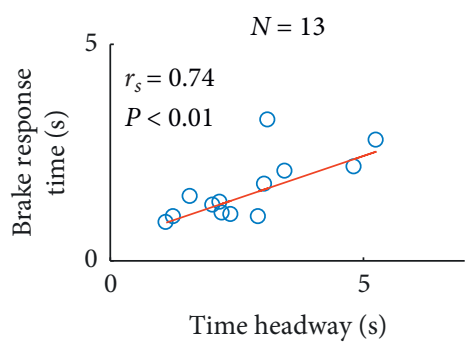

(c)

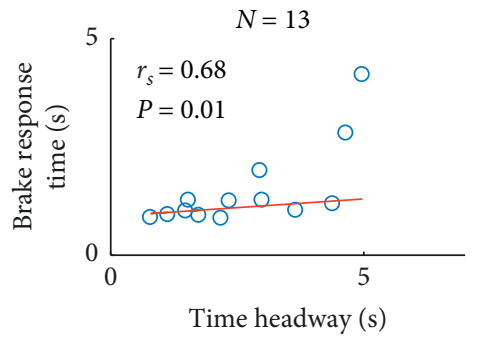

(d)

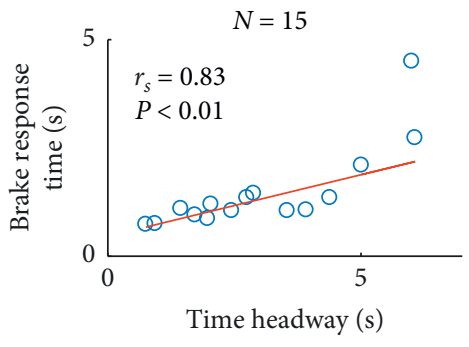

(e)

Figure 4: Drivers' brake response times as a function of time headway, in the first braking scenario. (a) No phone $N=23$. (b) Hhands-free (simple) $N=20$. (c) Hands-free (complex) $N=13$. (d) Handheld (simple) $N=13$. (e) Handheld (complex) $N=15$.

TABLE 3: Best parameterisation for accumulator model using $\dot{\theta}$ and $\tau^{-1}$, for the first braking scenario.

\begin{tabular}{lcc}
\hline Parameter & $\dot{\theta}$ & Looming signals \\
\hline$W_{l}$ & 37 & 8 \\
$W_{B}$ & 0.4 & -0.2 \\
$C_{B}$ & 0.14 & 0.22 \\
$C_{H F} S$ & 0 & 0 \\
$C_{H F \_}$ & 0 & 0 \\
$C_{H H_{-} S}$ & 0.04 & 0.14 \\
$C_{H H_{-} C}$ & 0.16 & 0.22 \\
$\sigma_{a}$ & 0.3 & 0.36 \\
AIC & 197.8 & 202.4 \\
\hline
\end{tabular}

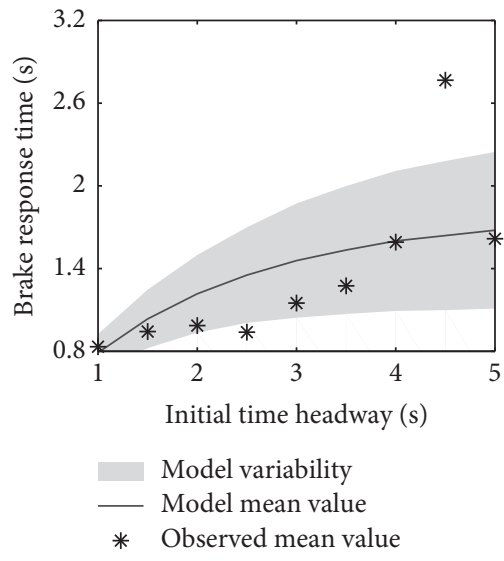

(a)

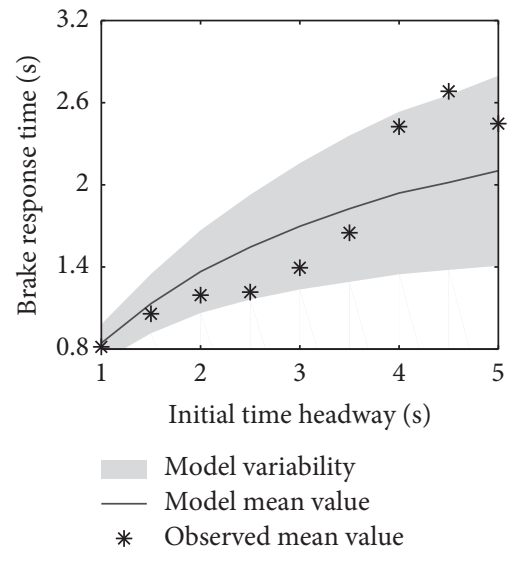

(b)

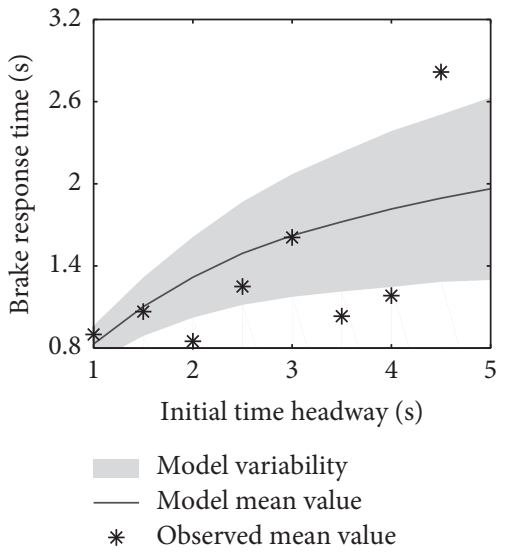

(c)

Figure 5: Continued. 


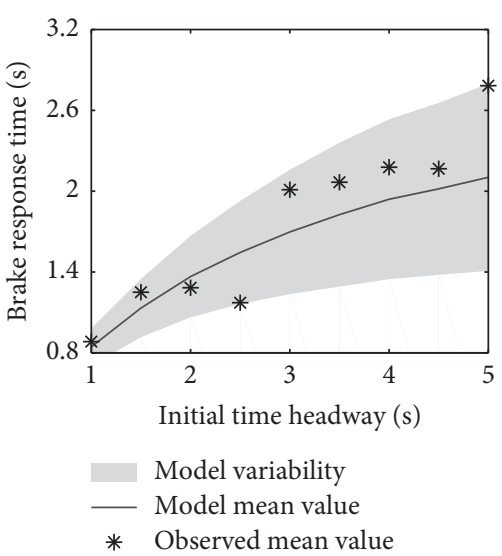

(d)

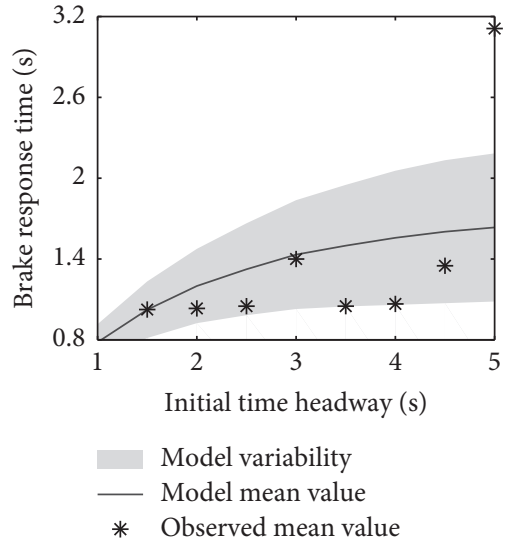

(e)

FIGURE 5: Simulation results versus observations obtained from simulator experiments, using $\dot{\theta}$. (a) No phone. (b) Hands-free (simple). (c) Handheld (simple). (d) Hands-free (complex). (e) Handheld (complex).

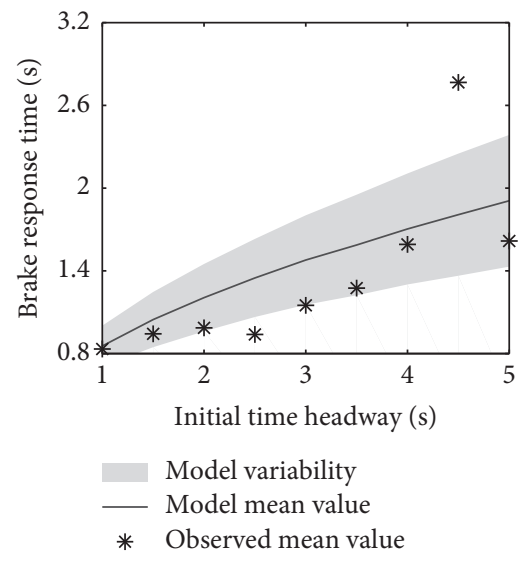

(a)

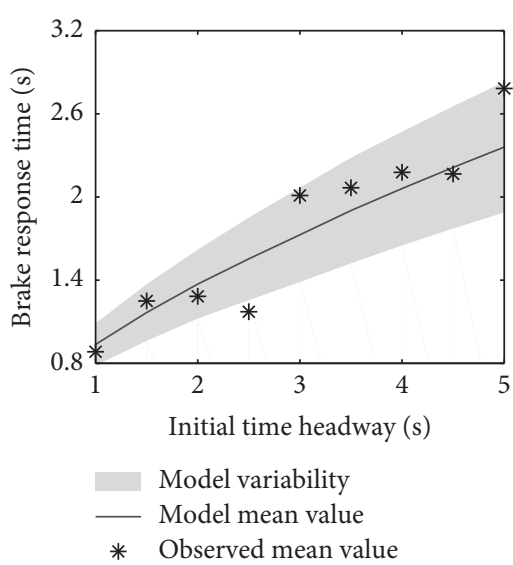

(d)

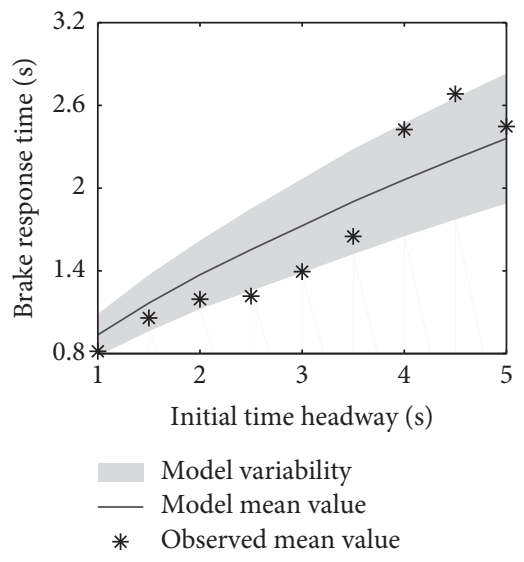

(b)

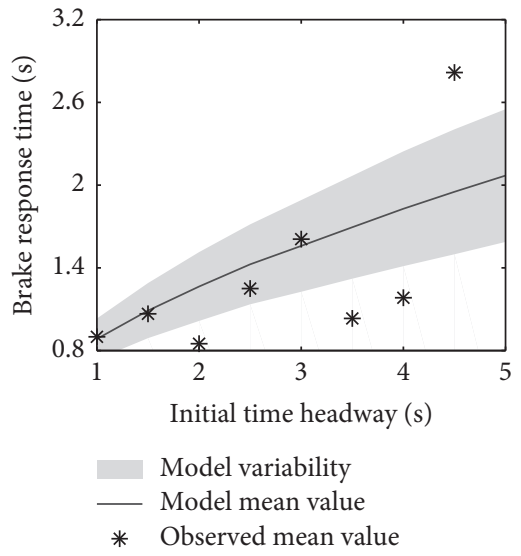

(c)

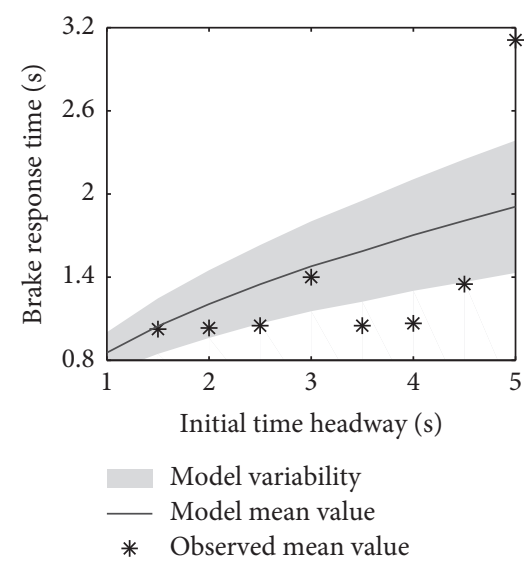

(e)

FIGURE 6: Simulation results versus observations obtained from simulator experiments, using $\tau^{-1} \cdot \dot{\theta}$. (a) No phone. (b) Hands-free (simple). (c) Handheld (simple). (d) Hands-free (complex). (e) Handheld (complex).

quantify visual looming, $\dot{\theta}$ and $\tau^{-1}$, both increase as the threat draws nearer. Although the two measures have been adopted in many previous studies $[38,39,40]$, few of them compared the two measures and drew a conclusion on the efficiency of the two measures in quantify looming. In both of the two braking scenarios designed in this study, 


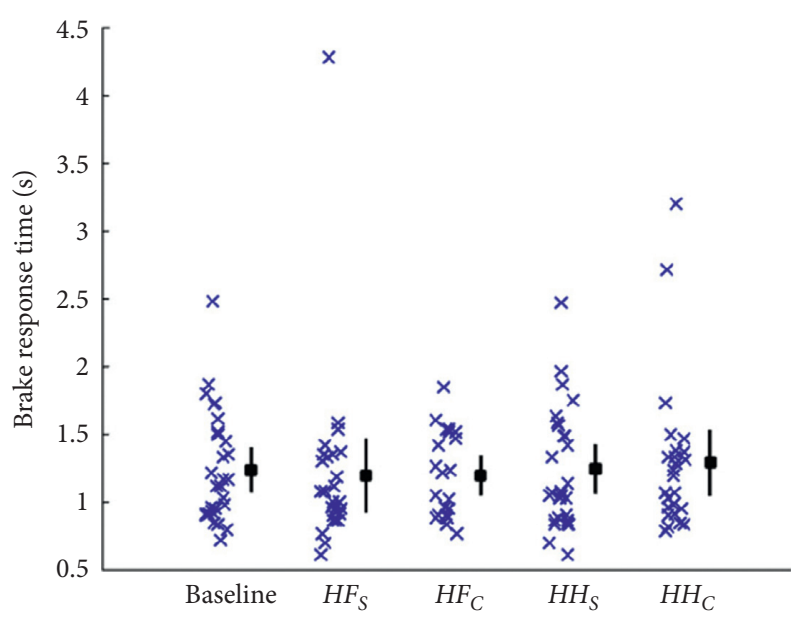

FIgURE 7: Drivers' brake responses to the second braking scenario under five conditions.

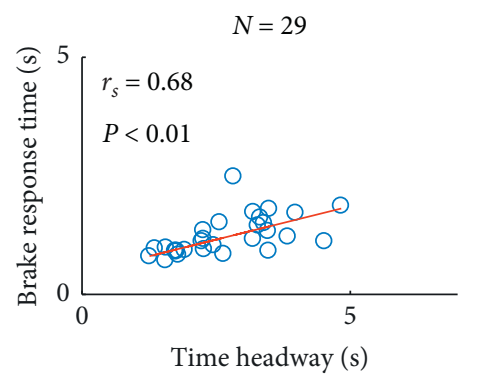

(a)

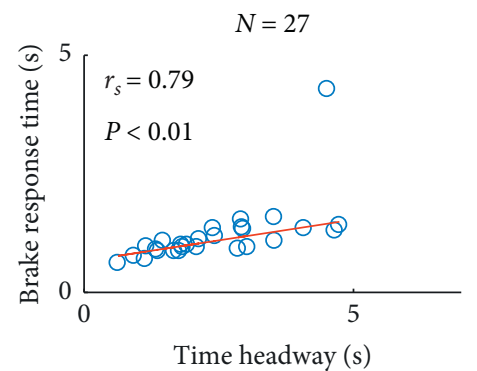

(b)

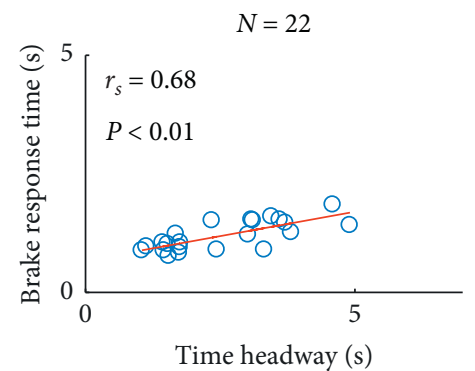

(c)

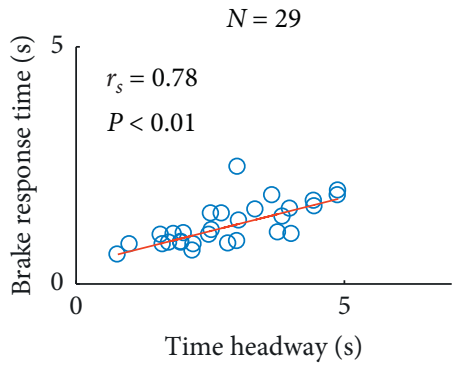

(d)

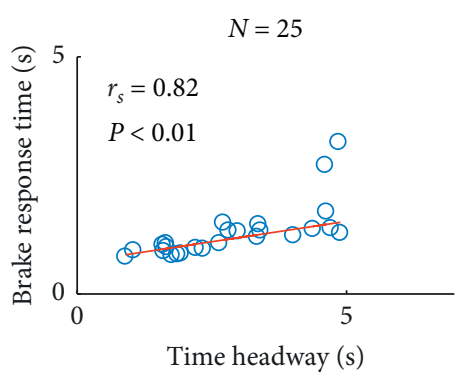

(e)

Figure 8: Drivers' brake response times as a function of time headway, in the second braking scenario. (a) No phone $N=29$. (b) Hands-free (simple) $N=27$. (c) Hands-free (complex) $N=22$. (d) handheld (simple) $N=29$. (e) Handheld (complex) $N=25$.

accumulator model fitted better by using $\tau^{-1}$ (see AIC values listed in Tables 3 and 4). Although in the first braking scenario, a smaller AIC was obtained for model fitted with $\theta$, the $\tau^{-1}$ AIC between the two models was in the range of four to seven, indicating that the $\tau^{-1}$ model could be plausible as well $[41,42]$. In this way, the results generated here were consistent with the findings in Xue et al. [35], which suggested that the visual looming information drivers adopted to take a brake response was more similar to $\tau^{-1}$.

Generally, in both of the two braking scenarios, drivers' mean BRTs and related variabilities increased with ITHWs in any conversation conditions. When making a brake decision, both cognitive loaded and nonloaded drivers have to rely on automatic responses to looming, and the time when looming accumulated to a threshold depends heavily on ITHW. If the looming at lead vehicle's onset is weak, that is, large ITHW, it would take a long time for drivers to accumulate to the threshold [35]. And a longer accumulation process allows more random drifts till reaching the accumulation threshold, which made the variabilities increased with increased ITHWs as well.

In addition, drivers' BRTs in hands-free conditions increased faster with the increase of ITHWs compared with baseline in the first braking scenario; that is, the effect of cognitive load on drivers' BRTs increased with the increase of ITHW. For example, when the ITHW equals $1.5 \mathrm{~s}$ and BRT was $0.94 \mathrm{~s}$ for baseline and $1.06 \mathrm{~s}$ for $\mathrm{HF}_{\mathrm{S}}$, the difference between the two conditions was $0.12 \mathrm{~s}$. But the difference between the two conditions could be $0.83 \mathrm{~s}$ (1.59s vs. $2.42 \mathrm{~s}$ ) when ITHW equals $4 \mathrm{~s}$. And the increased effect of cognitive 
TABLE 4: Best parameterisation for accumulator model of brake response time using $\dot{\theta}$ and $\tau^{-1}$, respectively.

\begin{tabular}{lcc}
\hline Parameter & $\dot{\theta}$ & Looming signals \\
\hline$W_{l}$ & 23 & 3 \\
$W_{B}$ & 0.2 & 0.2 \\
$C_{B}$ & 0.24 & 0.08 \\
$C_{H F \_}$ & 0.2 & 0.08 \\
$C_{H F \_}$ & 0.22 & 0.06 \\
$C_{H} H_{-} S$ & 0.24 & 0.06 \\
$C_{H H_{-} C}$ & 0.22 & 0.06 \\
$\sigma_{a}$ & 0.24 & 0.22 \\
AIC & 167.6 & 143.4 \\
\hline
\end{tabular}

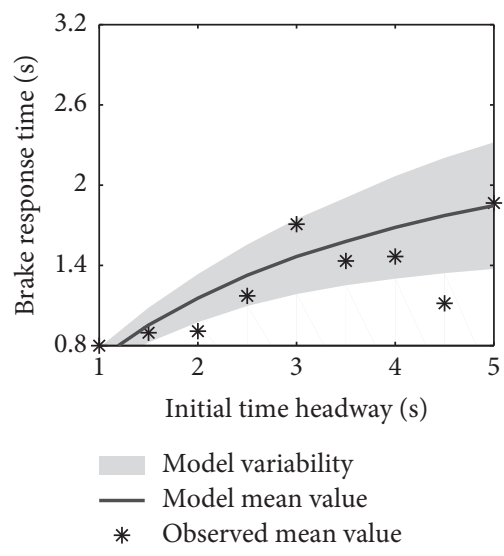

(a)

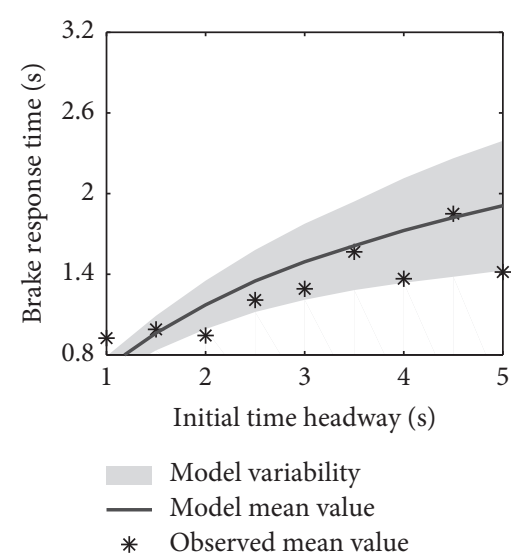

(d)

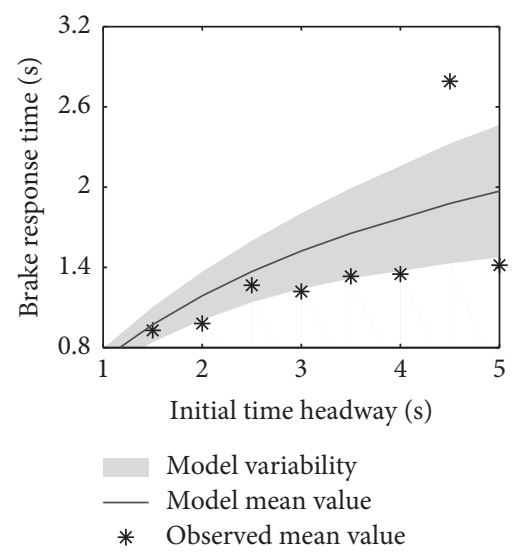

(b)

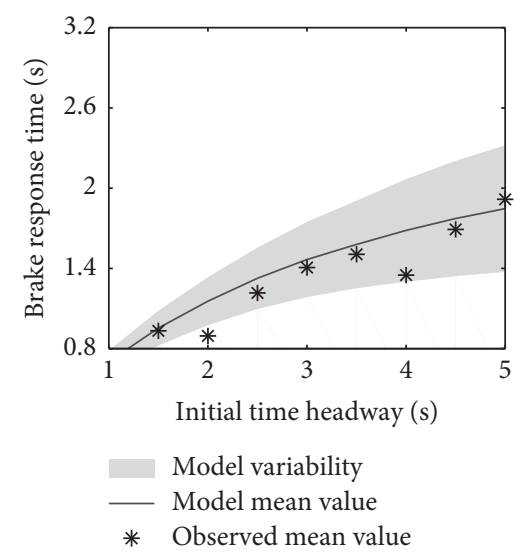

(c)

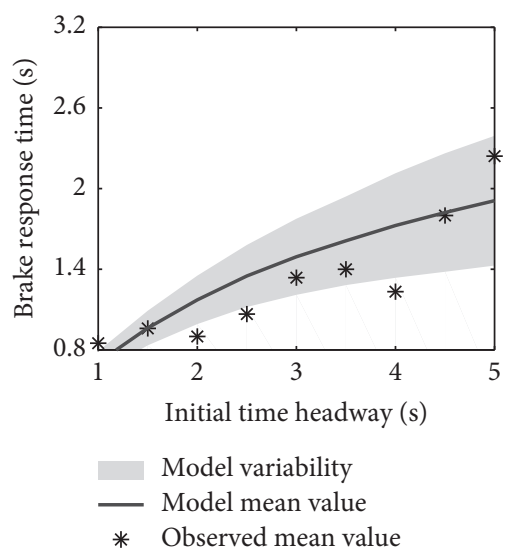

(e)

FIGURE 9: Simulation results versus observations obtained from simulator experiments, using $\dot{\theta}$. (a) No phone. (b) Hands-free (simple). (c) Handheld (simple). (d) Hands-free (complex). (e) Handheld (complex).

load on BRTs went slightly faster in $\mathrm{HF}_{\mathrm{c}}$ than in $\mathrm{HF}_{\mathrm{S}}$. According to the cognitive control hypothesis proposed by Engström et al. [43], cognitive load impaired aspects of driving rely on cognitive control but left the automatized aspects unaffected. Brake lights function as an alarm signal indicating the lead vehicle's brake; drivers were not likely to brake automatically once they saw the brake lights onset in their real-world driving. However, after repeated exposures to the lead vehicle's sudden brake, drivers may learn to brake once they saw the lead vehicle's brake lights onset. This aspect of stimuli-driven response can be regarded as cognitive control resources [44]. For a nonloaded driver, the driver's response partly relies on the top-down orienting of attention triggered by brake lights and partly relies on bottom-up driven by visual looming. However, for the cognitively distracted drivers, their abilities to respond to the brake lights were affected, which made them have to rely more on looming information. The findings here seemed to be consistent with the idea that cognitive load affects drivers' brake responses by impairing their use of specific predictive cues $[22,44,45]$. However, no significant increased effect of cognitive load on drivers' BRTs was found between baseline 


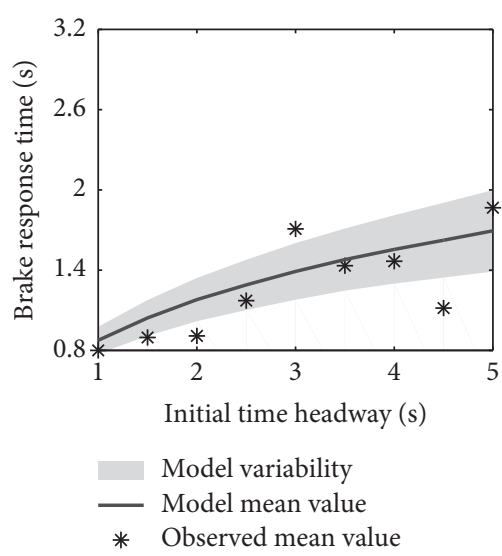

(a)

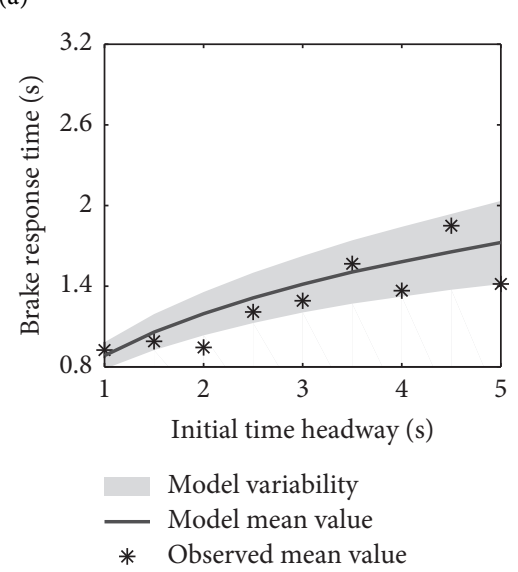

(d)

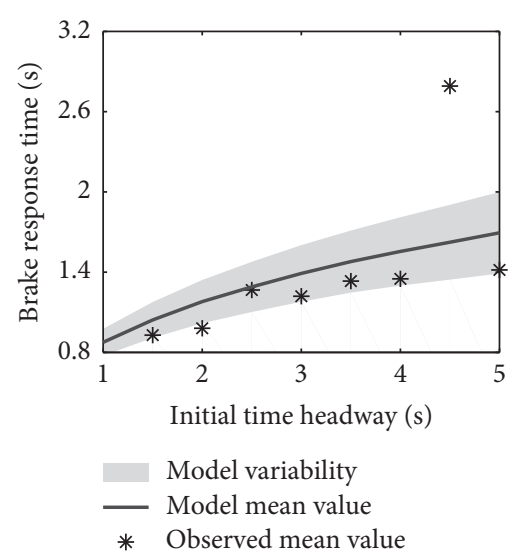

(b)

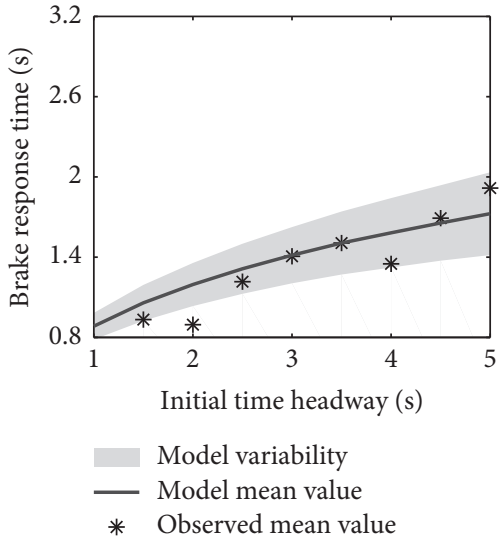

(c)

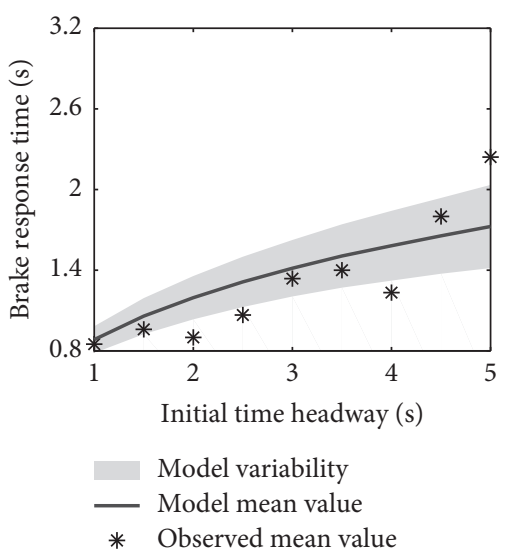

(e)

FIGURE 10: Simulation results versus observations obtained from simulator experiments, using $\tau^{-1}$. (a) No phone. (b) Hands-free (simple). (c) Handheld (simple). (d) Hands-free (complex). (e) Handheld (complex).

and handheld conversation conditions, reflected by the more parallel lines in Figures 5 and 6. For handheld conversations, drivers could be more cautious with their eyes always on the lead vehicle while driving. Once the lead vehicle's brake lights onset is seen, drivers may prefer to brake firstly while the secondary task is ignored. Drivers' eye movement behaviour could be investigated in further study to explore whether the results found in this paper were related to drivers' fixations on the lead vehicle.

It should be noticed that the increased effect of cognitive load on BRTs in the second braking scenario can be barely seen as well, whatever the phone mode and content are. No benefit of hands-free phone over hand-held phone was observed in this braking scenario. Two aspects could be taken into consideration with respect to the results obtained in the second braking scenario, that is, situation criticality and braking scenario exposure order, or a mixed strategy of them. Actually, the lead vehicle decelerated more moderately $\left(4 \mathrm{~m} / \mathrm{s}^{2}\right)$ in the first braking scenario compared with the second braking scenario $\left(6 \mathrm{~m} / \mathrm{s}^{2}\right)$. Looming in the second braking scenario thus increased faster, due to the harder brake induced by the lead vehicle. Drivers may rely more on automatic cues (visual looming) than brake lights, which made the cognitively loaded drivers less affected. Another possibility for this is the exposure order. The second braking scenario always came after the first one, which made the second braking scenario expected to some extent. Drivers' responses could be developed with expectation $[44,46]$, which made the difference between baseline and cognitive load conditions become relatively small. However, as the phone conversation was within subjects factor, the effects of repeated exposures on drivers' BRTs have not been examined in this study. The order of the phone conversations was counterbalanced between participants in this study; the number of samples included in each conversation for the stringently first unexpected brake was less than nine. The sample size was too small to conduct a statistic analysis. Besides, the effect of exposure order should be tested on the same situation criticality; the driving speed, lead vehicle's deceleration, and ITHW were different, that is why the effect of braking exposure order was not tested in this study.

\section{Conclusions}

Aiming to see how the situation criticality affects the effect of cognitive load on drivers' brake responses, a driving 
simulator experiment with two braking scenarios was thus conducted in this paper. Accumulator models fitting on both of the two braking scenarios with two measures $\left(\dot{\theta}\right.$ and $\left.\tau^{-1}\right)$ were compared. Overall models using $\tau^{-1}$ as the visual looming cue seemed to be preferable over the models using $\dot{\theta}$. And no benefit of hands-free phone over handheld phone on drivers' brake responses was observed in this study due to the situation criticality. A consistent conclusion could be drawn from both of the two braking scenarios; that is, the effect of cognitive load on drivers' BRTs decreased with the increase of situation criticality. Generally, results generated by the stochastic mechanism models in this paper replicated the key findings in Engström et al. [33] and demonstrated that the model could be used to model drivers' BRTs on different levels of cognitive load. The mechanistic model tested here can be adopted for the design of Forward Collision Warning (FCW) systems. By examining drivers' cognitive load and detecting the surrounding situation urgency, the timing of a FCW can thus be calculated and the strengths of FCW can be designed to better remind the drivers of the potential collisions.

\section{Data Availability}

The behavioural data used to support the findings of this study are restricted by the independent ethics committee (IRB) in order to protect the privacy of participants.

\section{Conflicts of Interest}

The authors declare that there are no conflicts of interest regarding the publication of this paper.

\section{Acknowledgments}

This research was supported by NCUT Start-Up Fund and National Natural Science Foundation of China (71771014, 71621001, and 71901036).

\section{References}

[1] National Road Safety Committee, New Zealand's Road Safety Strategy, National Road Safety Committee, Ministry of Transport, New Delhi, India, 2010.

[2] DGT, Statistical Yearbook of Accidents of the DirectorateGeneral for Traffic, DGT, Madrid, Spain, 2008.

[3] World Health Organization, Mobile Phone Use: A Growing Problem of Driver Distraction, World Health Organization, Geneva, Switzerland, 2011.

[4] D. Ascone, T. Lindsey, and C. Varghese, Traffic Safety Factor: An Examination of Driver Distraction as Recorded in NHTSA Databases, National Highway Traffic Safety Administration's National Center for Statistical and Analysis, Washington, DC, USA, 2009.

[5] F. Prat, M. E. Gras, M. Planes, S. Font-Mayolas, and M. J. M. Sullman, "Driving distractions: an insight gained from roadside interviews on their prevalence and factors associated with driver distraction," Transportation Research Part F: Traffic Psychology and Behaviour, vol. 45, pp. 194-207, 2017.
[6] M. S. Wogalter and C. B. Mayhorn, "Perceptions of driver distraction by cellular phone users and nonusers," Human Factors: The Journal of the Human Factors and Ergonomics Society, vol. 47, no. 2, pp. 455-467, 2005.

[7] R. Zhou, M. Yu, and X. Wang, "Why do drivers use mobile phones while driving? The contribution of compensatory beliefs," PLOS One, vol. 11, no. 8, Article ID e0160288, 2016.

[8] Cellular-News, "Countries that ban cell phone use while driving," 2007, http://www.cellular-news.com/carbans/.

[9] M. Sundeen, Cellphones and Highway Safety: 2005 State Legislative Update, National Conference of State Legislatures, Denver, CO, USA, 2005.

[10] National Highway Traffic Safety Administration, "Distraction.gov: state laws," National Highway Traffic Safety Administration, Washington, DC, USA, 2014.

[11] I. A. Al-Darrab, Z. A. Khan, and S. I. Ishrat, "An experimental study on the effect of mobile phone conversation on drivers' reaction time in braking response," Journal of Safety Research, vol. 40, no. 3, pp. 185-189, 2009.

[12] L. Angell, J. Auflick, P. A. Austria et al., "Driver workload metrics project, task 2," Final Report, National Highway Traffic Safety Administration, Washington, DC, USA, 2006.

[13] W. Consiglio, P. Driscoll, M. Witte, and W. P. Berg, "Effect of cellular telephone conversations and other potential interference on reaction time in a braking response," Accident Analysis \& Prevention, vol. 35, no. 4, pp. 495-500, 2003.

[14] M. M. Haque and S. Washington, "The impact of mobile phone distraction on the braking behaviour of young drivers: a hazard-based duration model," Transportation Research Part C: Emerging Technologies, vol. 50, pp. 13-27, 2015.

[15] B. Metz, A. Landau, and V. Hargutt, "Frequency and impact of hands-free telephoning while driving - results from naturalistic driving data," Transportation Research Part F: Traffic Psychology and Behaviour, vol. 29, pp. 1-13, 2015.

[16] M. Saifuzzaman, M. M. Haque, Z. Zheng, and S. Washington, "Impact of mobile phone use on car-following behaviour of young drivers," Accident Analysis \& Prevention, vol. 82, pp. 10-19, 2015.

[17] H. Xiong, S. Bao, J. Sayer, and K. Kato, "Examination of drivers' cell phone use behavior at intersections by using naturalistic driving data," Journal of Safety Research, vol. 54, pp. 89-93, 2015.

[18] W. Yan, W. Xiang, S. C. Wong, X. Yan, Y. C. Li, and W. Hao, "Effects of hands-free cellular phone conversational cognitive tasks on driving stability based on driving simulation experiment," Transportation Research Part F: Traffic Psychology and Behaviour, vol. 58, pp. 264-281, 2018.

[19] P. Burns, A. Parkes, S. Burton, R. Smith, and D. Burch, "How dangerous is driving with a mobile phone? Benchmarking the impairment to alcohol," TRL Report, vol. 547, 2002.

[20] D. L. Strayer and F. A. Drew, "Profiles in driver distraction: effects of cell phone conversations on younger and older drivers," Human Factors: The Journal of the Human Factors and Ergonomics Society, vol. 46, no. 4, pp. 640-649, 2004.

[21] D. L. Strayer and W. A. Johnston, "Driven to distraction: dualtask studies of simulated driving and conversing on a cellular telephone," Psychological Science, vol. 12, no. 6, pp. 462-466, 2001.

[22] J. W. Muttart, D. L. Fisher, M. Knodler, and A. Pollatsek, "Driving without a clue: evaluation of driver simulator performance during hands-free cell phone operation in a work zone," Transportation Research Record: Journal of the Transportation Research Board, vol. 2018, no. 1, pp. 9-14, 2007. 
[23] J. K. Caird, C. R. Willness, P. Steel, and C. Scialfa, "A metaanalysis of the effects of cell phones on driver performance," Accident Analysis \& Prevention, vol. 40, no. 4, pp. 1282-1293, 2008.

[24] M. M. Haque and S. Washington, "A parametric duration model of the reaction times of drivers distracted by mobile phone conversations," Accident Analysis \& Prevention, vol. 62, pp. 42-53, 2014.

[25] J. He, A. Chaparro, B. Nguyen et al., "Texting while driving: is speech-based text entry less risky than handheld text entry?" Accident Analysis \& Prevention, vol. 72, pp. 287-295, 2014.

[26] C. J. D. Patten, A. Kircher, J. Östlund, and L. Nilsson, "Using mobile telephones: cognitive workload and attention resource allocation," Accident Analysis and Prevention, vol. 36, pp. 341-350, 2004.

[27] A. Benedetto, A. Calvi, and F. D’Amico, "Effects of mobile telephone tasks on driving performance: a driving simulator study," Advances in Transportation Studies, vol. 26, pp. 29-44, 2012.

[28] O. Oviedo-Trespalacios, M. M. Haque, M. King, and S. Washington, "Understanding the impacts of mobile phone distraction on driving performance: a systematic review," Transportation Research Part C: Emerging Technologies, vol. 72, pp. 360-380, 2016.

[29] X. Li, O. Oviedo-Trespalacios, A. Rakotonirainy, and X. Yan, "Collision risk management of cognitively distracted drivers in a car-following situation," Transportation Research Part F: Traffic Psychology and Behaviour, vol. 60, pp. 288-298, 2019.

[30] K. Lipovac, M. Đerić, M. Tešić, Z. Andrić, and B. Marić, "Mobile phone use while driving-literary review," Transportation Research Part F: Traffic Psychology and Behaviour, vol. 47, pp. 132-142, 2017.

[31] P. Choudhary and N. R. Velaga, "Modelling driver distraction effects due to mobile phone use on reaction time," Transportation Research Part C: Emerging Technologies, vol. 77, pp. 351-365, 2017.

[32] J. Engström, "Scenario criticality determines the effects of working memory load on brake response time," in Proceedings of the European Conference on Human Centred Design for Intelligent Transport Systems, pp. 25-36, Lyon, France, September 2010.

[33] J. Engström, G. Markkula, Q. Xue, and N. Merat, "Simulating the effect of cognitive load on braking responses in lead vehicle braking scenarios," IET Intelligent Transport Systems, vol. 12, no. 6, pp. 427-433, 2018.

[34] H. Alm and L. Nilsson, "The effects of a mobile telephone task on driver behaviour in a car following situation," Accident Analysis \& Prevention, vol. 27, no. 5, pp. 707-715, 1995.

[35] Q. Xue, G. Markkula, X. Yan, and N. Merat, "Using perceptual cues for brake response to a lead vehicle: comparing threshold and accumulator models of visual looming," Accident Analysis \& Prevention, vol. 118, pp. 114-124, 2018.

[36] G. Markkula, "Modeling driver control behavior in both routine and near-accident driving," Proceedings of the Human Factors and Ergonomics Society Annual Meeting, vol. 58, no. 1, pp. 879-883, 2014.

[37] D. N. Lee, "A theory of visual control of braking based on information about time-to-collision," Perception, vol. 5, no. 4, pp. 437-459, 1976.

[38] D. Lamble, T. Kauranen, M. Laakso, and H. Summala, "Cognitive load and detection thresholds in car following situations: safety implications for using mobile (cellular) telephones while driving," Accident Analysis \& Prevention, vol. 31, no. 6, pp. 617-623, 1999.
[39] M. E. Maddox and A. Kiefer, "Looming threshold limits and their use in forensic practice," in Proceedings of the Human Factors and Ergonomics Society Annual Meeting, vol. 56, no. 1, pp. 700-704, 2012.

[40] G. Markkula, J. Engström, J. Lodin, J. Bärgman, and T. Victor, "A farewell to brake reaction times? Kinematics-dependent brake response in naturalistic rear-end emergencies," Accident Analysis \& Prevention, vol. 95, pp. 209-226, 2016.

[41] I. W. Evett and B. S. Weir, Interpreting DNA Evidence: Statistical Genetics for Forensic Scientists, Sinauer Associates, Sunderland, MA, USA, 1998.

[42] K. P. Burnham, D. R. Anderson, and K. P. Huyvaert, "AIC model selection and multimodel inference in behavioral ecology: some background, observations, and comparisons," Behavioral Ecology and Sociobiology, vol. 65, no. 1, pp. 23-35, 2011.

[43] J. Engström, G. Markkula, T. Victor, and N. Merat, "Effects of cognitive load on driving performance: the cognitive control hypothesis," Human Factors: The Journal of the Human Factors and Ergonomics Society, vol. 59, no. 5, pp. 734-764, 2017.

[44] J. Engström, M. L. Aust, and M. Viström, "Effects of working memory load and repeated scenario exposure on emergency braking performance," Human Factors: The Journal of the Human Factors and Ergonomics Society, vol. 52, no. 5, pp. 551-559, 2010.

[45] M. R. K. Baumann, T. Petzoldt, J. Hogema, and J. F. Krems, "The effect of cognitive tasks on predicting events in traffic," in Proceedings of the European Conference on Human Centred Design for Intelligent Transport Systems, C. Brusque, Ed., Humanist, Lyon, France, pp. 3-11, April 2008.

[46] J. D. Lee, D. V. McGehee, T. L. Brown, and M. L. Reyes, "Collision warning timing, driver distraction, and driver response to imminent rear-end collisions in a high-fidelity driving simulator," Human Factors: The Journal of the Human Factors and Ergonomics Society, vol. 44, no. 2, pp. 314-334, 2002. 